\title{
G-protein-Coupled Receptors and Their (Bio) Chemical Significance Win 2012 Nobel Prize in Chemistry
}

\author{
Hsi-Hsien Lin
}

\begin{abstract}
G-protein-coupled receptors (GPCRs) are seven transmembrane cell surface proteins specialized in cellular communication. These receptors represent a major gateway through which cells convert external cues into intracellular signals and respond with appropriate actions. While the effects of hormones, neurotransmitters, and drugs on cells, tissues, organs, and even whole organisms are well described, the molecular identity of the direct targets and the diverse signaling mechanisms of these biological ligands have been slow and hard to define. The Nobel Prize in Chemistry for the year 2012 acknowledges the importance of GPCRs in these processes, especially for the contribution of Profs Robert J. Lefkowitz and Brian K. Kobilka to the studies of GPCRs. In this brief review, the seminal works accomplished by the two GPCR pioneers are summarized and the (bio) chemical significance of GPCRs in health and disease is discussed. (Biomed J 2013;36:118-124)
\end{abstract}

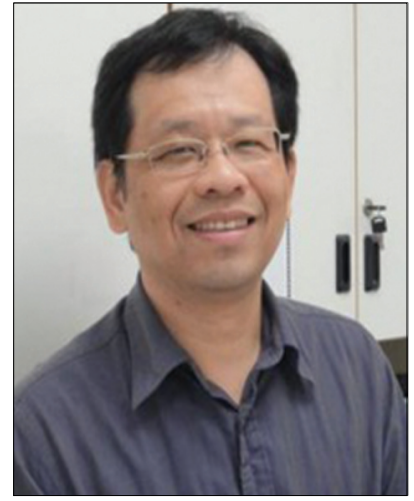

Prof. Hsi-Hsien Lin

\section{Key words: G protein, G-protein-coupled receptors, ligand, receptor desensitization, signaling pathway, structure}

$\mathrm{T}_{\mathrm{t}, \mathrm{s}}^{\mathrm{b}}$ he human genome encodes more than 800 G-protein-coupled receptors (GPCRs) that form the largest receptor family among all cell surface proteins ${ }^{[1,2]}$ GPCRs are responsible for every aspect of human biology from vision, taste, sense of smell, sympathetic and parasympathetic nervous functions, metabolism, and immune regulation to reproduction. ${ }^{[3]}$ Furthermore, $~ 40 \%$ of all pharmaceutical drugs are known to target GPCRs. ${ }^{[4,5]}$ It is therefore not surprising that the 2012 Nobel Prize was awarded to Drs. Robert J. Lefkowitz and Brian K. Kobilka for their contribution to the studies of GPCRs. What is less understood is the category of prize they received: Chemistry.

In fact, GPCR-related researchers have a rather long relationship with the Nobel Prize [Figure 1]. In 1967, Ragnar Granit, Haldan Keffer Hartline, and George Wald were awarded the Nobel Prize in Physiology or Medicine for their discoveries concerning the physiological and chemical visual processes in the eye. Sir Bernard Katz, Ulf von Euler, and Julius Axelrod received the same Prize in
1970 for their studies of the neurotransmitters in the nerve terminals and the mechanism for their storage, release, and inactivation. Earl Wilbur Sutherland Jr. discovered cyclic AMP as the second messenger for mediating the action of hormones and won the 1971 Prize. Sir James W. Black received the Nobel Prize in 1988 for the discovery of propranolol and cimetidine, two clinical drugs that block the action of the $\beta$-adrenergic receptor ( $\beta$ ARs) and the $\mathrm{H}_{2}$ histamine receptor, respectively. In 1994, for the discovery of G-proteins and their role in signal transduction in cells, Alfred G. Gilman and Martin Rodbell were honored with the Prize. Arvid Carlsson received the same recognition for his work on dopamine in 2000. Richard Axel and Linda B. Buck were the recipients of the 2004 Prize for their work on odorant receptors and the olfactory system [Figure 1]. ${ }^{[6]}$

Interestingly, these previous works were more concerned about the physiological relevance and clinical aspects of GPCR-related issues, and were all awarded the Nobel Prize in Physiology or Medicine. Instead,

From the Department of Microbiology and Immunology, College of Medicine, Chang Gung University, Taoyuan, Taiwan Received: Jan. 31, 2013; Accepted: May 05, 2013

Correspondence to: Prof. Hsi-Hsien Lin, Department of Microbiology and Immunology, College of Medicine, Chang Gung University. 259 Wenhua $1^{\text {st }}$ Rd., Gueishan, Taoyuan, Taiwan. Tel: 886-3-2118800 ext. 3321; Fax: 886-3-2118469; E-mail: hhlin@ mail.cgu.edu.tw

DOI: $10.4103 / 2319-4170.113233$ 


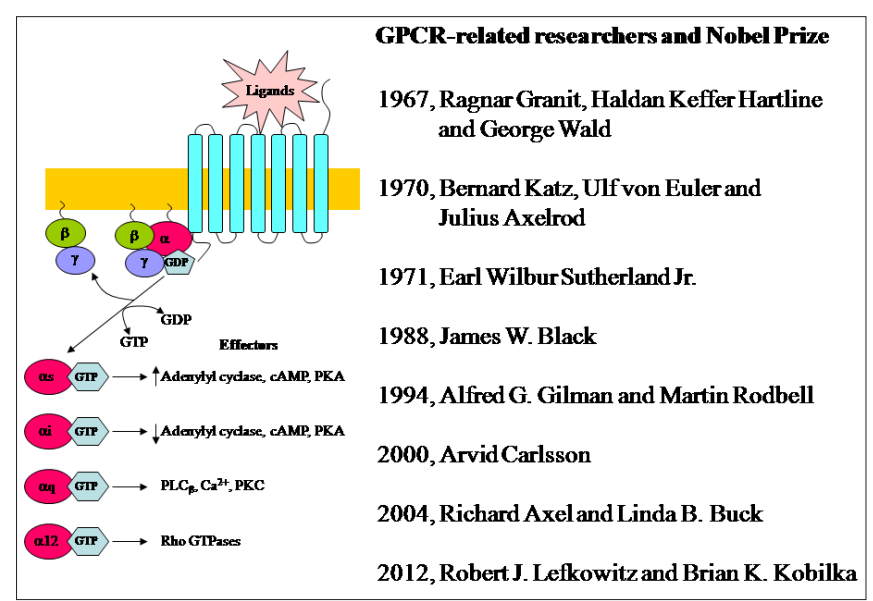

Figure 1: The general model of GPCR-mediated ligand interaction and signal transduction. The classification of $G$ proteins and the downstream effector molecules are listed. Nobel Prizes awarded to GPCR-related studies are also listed at the right panel

Drs. Lefkowitz and Kobilka took a molecular and structural approach to reveal the most basic biochemical and mechanistic detail of GPCR function. ${ }^{[6-8]}$ Their work provides a chemical insight into the way GPCRs receive and deliver cellular signals across the plasma membrane. Most importantly, due to their discoveries, the therapeutic potential of GPCRs can now be more efficiently mined. They indeed fully deserve the Chemistry Prize, albeit with a medical flavor.

\section{The pathway that leads GPCRs to the Nobel Prize}

How a cell mediates the exchange of extracellular information into intracellular chemical messages has puzzled generations of scientists. Although the concept of ligand-activated receptor was noted more than a century ago, the molecular identification and characterization of receptor molecules has been slow to say the least. ${ }^{[9]}$ In 1970s, Prof. Lefkowitz was one of the first to demonstrate successfully the existence of specific cell surface receptors for endocrine hormones. ${ }^{[10-12]}$ By using chemically synthesized radioactive ligands, he showed the specific binding of adrenocortiotropic hormone (ACTH) and epinephrine to distinct receptors that are able to activate adenylyl cyclase. ${ }^{[10-12]}$ He later focused on the studies of $\beta$ ARs and proposed the ternary complex model to explain how cells convert extracellular stimuli into intracellular signals. ${ }^{[13]}$ This model dictated that the ligand-receptor interaction leads to the formation of a high-affinity receptor complex where a cell surface receptor is coupled at both ends to the extracellular agonist (ligand) and intracellular G-protein, respectively. ${ }^{[13]}$

The isolation and purification of functional $\beta A R$ was achieved some years later after efficient detergent solubilization, followed by ligand-specific affinity chromatography. ${ }^{[14,15]}$ The functional identity of the isolated receptor was proven after reconstitution of the purified receptor with $G$ proteins and adenylyl cyclase. ${ }^{[16,17]}$ Subsequent $\mathrm{N}$-terminal amino acid sequencing revealed unique peptide sequences from which degenerate oligonucleotide probes were derived, allowing Prof. Kobilka to successfully clone the $\beta$ AR gene. ${ }^{[18,19]}$ The delineation of the full-length $\beta$ AR protein sequence uncovered a major structural surprise: The presence of the seven transmembrane (7TM) helices that shared some sequence similarity with the visual pigment protein rhodopsin. ${ }^{[9,20]}$ Rhodopsin, a 7TM cell surface protein, was already a well-known G-protein-linked receptor at the time. ${ }^{[21,22]}$ Thus, a structural signature was appreciated among light-sensitive proteins and hormone and neurotransmitter receptors. This realization and molecular cloning of other G-protein-linked receptor genes finally cemented the common 7TM structural feature for the GPCR family. ${ }^{[3,9,20]}$

With the development of molecular cloning techniques in the 1980s, site-directed mutagenesis and chimeric receptors were employed to reveal the structural-functional relationship of GPCRs..$^{[9,20,23]}$ These studies identified specific receptor sub-domains important for ligand binding and G-protein coupling. ${ }^{[24,25]}$ In addition, constitutively active receptors were discovered when specific residues were mutated, providing a relevant insight into specific human diseases. ${ }^{\left[{ }^{26]}\right.}$ During the same period, another convergent theme was also noted among many GPCRs, namely ligand-induced receptor phosphorylation and inactivation or desensitization. ${ }^{[9,20,23]}$ The identification of GPCR kinases (GRKs) and $\beta$-arrestins not only provided molecular explanation for GPCR desensitization but also led to the demonstration of G-protein-independent signaling mechanisms as well as GPCR endocytosis and recycling. It is accepted now that G proteins, in fact, represent only part of the signaling adaptors used by GPCRs. ${ }^{[27,28]}$

Structural-functional analysis also noted distinct structural alterations in different states of receptor activation. To achieve this, a multitude of biochemical and biophysical methods were developed and employed to dissect the structural transitions of receptors. ${ }^{[9,20,23]}$ It was appreciated from these studies that the structural alterations are key to the understanding of receptor activation mechanism. ${ }^{[29,30]}$ Thus, a high-resolution structure of GPCRs was necessary for the detailed analysis of the conformational changes in activated and non-activated states, even though it is notoriously difficult to crystallize the membrane proteins. Dr. Palczewski and colleagues were the first to solve the 3D structure of bovine rhodopsin, a highly enriched GPCR in bovine rod outer segment membranes, providing initial insights into the localization of the TM helices in the mem- 
brane. ${ }^{[31]}$ Soon after, a major breakthrough was achieved when Kobilka's laboratory reported the crystal structure of inverse agonist-bound $\beta$ AR that was stabilized by an antibody in a lipid environment. ${ }^{[32]}$ This was quickly followed by a more defined structure from the same group after an engineered $\beta$ AR-T4 lysozyme fusion protein generated a better crystal. ${ }^{[33,34]}$ Finally, the structure of an active ternary receptor complex containing agonist-bound $\beta$ AR coupled to $\mathrm{G}$ proteins was solved in 2011 by Kobilka and colleagues. ${ }^{[35]}$ When compared with the structure of non-activated $\beta A R$, the conformational changes in the activated receptor revealed a sequential event leading to the activation of $G$ protein. In short, ligand binding induced a major displacement of the $6^{\text {th }}$ TM segment of receptor, exposing a hydrophobic cleft into which the $\mathrm{C}$-terminal helix of $\mathrm{G} \alpha$ protein was able to insert. This interaction in turn changed the $\mathrm{G}$ protein structure, eventually leading to its activation. ${ }^{[6-8]}$

The biochemical methodologies developed for the $\beta$ AR structural study are now being adapted and applied to solve the structure of other GPCRs. With the detailed 3D structure of the active ternary $\beta$ AR complex and others, it is possible to screen for better small molecule agonist/ antagonist/inverse agonist more efficiently. This should revolutionize the development of pharmacologic research for drugs targeting GPCRs.

\section{GPCRs and their (bio) chemical significance}

The aforementioned summary of the groundbreaking work done by the two Nobel Laureates has emphasized the general biological importance of GPCRs. The following sections will focus on the specific aspects that highlight the (bio) chemical significance of GPCRs in health and disease.

\section{Ligands}

GPCRs are known to interact with a plethora of ligands ranging from photons, ions, amino acids, odorants, pheromones, eicosanoids, neurotransmitters, peptides, proteins, and hormones. ${ }^{[3,36]}$ Thus, a wealth of chemical signals can be deciphered by distinct GPCRs. This versatile ability is in part determined by the diversity in receptor protein sequences that share different degrees of similarity or phylogenetic relationship. Recently, the GRAFS classification system grouped all human GPCRs into Glutamate, Rhodopsin, Adhesion, Frizzled/Taste, and Secretin families based on the phylogenetic criteria. ${ }^{[1]}$ Interestingly, natural ligands to the individual GPCR families also seem to vary considerably. For example, most Glutamate-class GPCRs bind to amino acids, cations, or small organic compounds, the Secretin-class receptors interact mostly with peptide or protein hormone, while the Rhodopsin-class receptors can couple with substances such as photons, nucleotides, lipid-like compounds, peptides, and proteins (including enzymes). The Adhesion-class GPCRs are known to interact with cell surface or extracellular matrix proteins, glycosaminoglycans, or even microbial ligands. ${ }^{[1]}$ Nevertheless, for the majority of GPCRs, the identity of their natural ligands is still unknown, hence remain orphan receptors.

In general, based on their effect on the receptor function, ligands can be classified as agonists, antagonists, or inverse agonists..$^{[5,36]}$ Agonists exert a positive signaling response, while inverse agonists decrease constitutive signaling activity. Antagonists compete and inhibit the binding of agonists but do not produce any response by themselves. Studies have shown that while many GPCR ligands are found to be full agonists, quite a few, in fact, function as partial agonists suggesting that ligand-induced GPCR activation is more complex than predicted previously. The reason for such differential activations might be explained by the fact that GPCRs may adopt multiple conformational states with different signaling

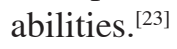

Molecular studies have shown that while ligand binding activates GPCRs by commonly inducing a conformational change in the 7TM core domain, they do so through rather diverse mechanisms. ${ }^{[37]}$ Most small ligands bind in a cavity formed within the TM region, but peptide and protein ligands might also interact with the N-terminal region and the extracellular loops. In the case of rhodopsin, photon, in fact, activates retinol molecule that is covalently linked in the TM cavity, changing its conformation from cis to trans configuration to activate the receptor. ${ }^{[38-41]}$ In protease-activated receptors (PARs), activation is brought about by the proteolytic cleavage of the $\mathrm{N}$-terminus of receptors by serine proteases (such as thrombin and trypsin). Part of the newly cleaved receptors then act as an agonist that in turn binds and activates the receptors. ${ }^{[2,43]}$ Thus, it seems that GPCRs have evolved successfully to adapt various mechanisms to respond to a diverse array of ligands for activation. Indeed, GPCRs represent a treasure trove for ligand identification and potential drug targets. ${ }^{[4,44,45]}$

\section{Conformational (structural) variants of GPCRs}

The conventional view of GPCR activation is that the receptor exists in two conformational states: Inactive and active. Agonist binding stabilized the active form of the receptor, while inverse agonist secured the inactive form. Intracellular signaling is achieved by the active conformation that allowed the efficient coupling and activation of $G$ proteins and downstream adaptor molecules.

However, recent studies have suggested that the mechanisms of receptor activation are far more complex than the simple biomodal switch system. ${ }^{[46-48]}$ First of all, multiple (more than two) conformational variants of GP- 
CRs are likely to be present in equilibrium in the plasma membrane. Each GPCR conformation can potentially interact with selective ligands and couple to specific intracellular signaling complexes, finally leading to different functional phenotypes. Hence, different ligands selectively bind to and stabilize the same GPCR at specific conformational states that activate different sets of signaling molecules, producing different cellular effects. ${ }^{[23]}$

This ligand-induced selective signaling (LiSS) is also referred to by others as functional selectivity or biased agonism. ${ }^{[23]}$ The LiSS concept provides an explanation as to why a single GPCR can induce different response patterns by multiple ligands and the existence of so-called full and partial agonists. This realization has led to new opportunities in selective drug design and implications for GPCR deorphanization.

\section{Diverse signaling mediators and pathways}

By definition, the large heterotrimeric G-protein complex $\left(\mathrm{G}_{\alpha \beta \gamma}\right)$ is traditionally thought of as the canonical mediator responsible for initiating the signal transduction of GPCRs. ${ }^{[3]}$ The conformational change induced by ligand binding recruits and activates $G$ protein by replacing GDP with GTP on the $G_{\alpha}$ subunit, which dissociates from the tightly bound $\mathrm{G}_{\beta \gamma}$ subunits. $\mathrm{G}_{\alpha-\mathrm{GTP}}$ and $\mathrm{G}_{\beta \gamma}$ subunits then individually initiate different signaling pathways involving various second messengers and effector proteins. The $\mathrm{G}_{\alpha \text {-GTP }}$ subunit is then re-associated with $\mathrm{G}_{\beta \gamma}$ subunits after hydrolysis of GTP to GDP by its inherent GTPase activity as well as numerous GTPase-activating proteins (GAPs), allowing a new signaling cycle to start [Figure 1]. ${ }^{[2,3,49]}$

$\mathrm{G}$ protein can be divided into four major classes based on the functional characteristics of $G_{\alpha}$ subunits: $G_{\alpha s}, G_{\alpha i / \rho}$, $\mathrm{G}_{\alpha \mathrm{q} / 111}$, and $\mathrm{G}_{\alpha 12 / 13} \cdot \mathrm{G}_{\alpha \mathrm{s}}$ stimulates the effector enzyme, adenylyl cyclase, to catalyze the production of cAMP from ATP. This initiates a cAMP-dependent pathway leading to the activation of protein kinase A (PKA), which is able to phosphorylate multiple downstream targets. In contrast, $\mathrm{G}_{\alpha \mathrm{i}}$ subunit inhibits the production of cAMP. $\mathrm{G}_{\alpha \mathrm{q} / 11}$ subunit activates phospholipase $\mathrm{C}-\beta\left(\mathrm{PLC}_{\beta}\right)$, which cleaves phosphatidylinositol 4,5-biphosphate ( PIP $_{2}$ ) into inositol-1,4,5-trisphosphate $\left(\mathrm{IP}_{3}\right)$ and diacylglycerol (DAG). IP 3 and DAG are two second messengers that activate the release of $\mathrm{Ca}^{2+}$ and protein kinase $\mathrm{C}$, respectively, promoting further signaling cascades. $\mathrm{G}_{\alpha 12 / 13}$ subunit acts through RhoGEF to activate Rho GTPase family members and regulate actin cytoskeleton remodeling to modulate cell migration. In addition, dissociated $\mathrm{G}_{\beta \gamma}$ subunits are also known to activate effector molecules such as ion channels and PLC $_{\beta}$, thus inducing independent signaling pathways. ${ }^{[50-52]}$

In recent years, alternatives to the canonical GPCR signaling pathways that expand and/or fine-tune GPCR activity have been identified. GPCRs are known to be phosphory- lated by GRKs in a stimulus-dependent manner. Receptor phosphorylation induces $\beta$-arrestin binding, which downregulates and desensitizes receptor activity ${ }^{[53,54]}$ Later, it was shown that $\beta$-arrestins are also involved in clathrin-mediated receptor endocytosis and G-protein-independent signaling by interacting with other signaling machineries such as the Src family, mitogen-activated protein kinases (MAPKs), and phosphatidylinositol 3-kinase (PI3K). ${ }^{[27,55,56]}$

In addition, it has recently been shown that some GPCRs can also signal in a G-protein-independent and $\beta$-arrestin-independent mechanism by interacting with other GPCR-interacting partners such as JAK2 and PDZ domain-containing protein $\mathrm{Na}^{+}-\mathrm{H}^{+}$exchange regulatory factor 1 (NHERF1). ${ }^{[28]}$ More interestingly, some GPCR-interacting partners can also modulate G-protein-dependent signaling positively or negatively by acting as scaffolds to couple downstream signaling molecules closer to GPCRs and $G$ proteins to increase the signaling efficiency or by interfering with GPCR-G protein association to reduce/inhibit G-protein-mediated signaling. ${ }^{[28]}$ Apart from the various signaling mediators and pathways, GPCRs are also known to mediate functional "cross-talk" with other cell surface receptors. GPCR activation, hence, can transactivate other non-GPCR receptors. The best example is the cross-talk between GPCRs and the growth factor receptors. ${ }^{[44,49,57,58]}$ GPCR signaling induced the activity of cell surface sheddases (e.g., matrix metalloproteinases), which cleaved membrane-bound growth factors and led to the activation of growth factor receptors. ${ }^{[59]}$ GPCR activation also can lead to the so-called inside-out signaling of integrin by inducing conformational changes in the extracellular domain and enhancing the ligand-binding affinity of integrins through modification of the intracellular region. ${ }^{[60-62]}$

\section{Functional and expressional regulation of GPCRs}

GPCR activity might be modulated through other mechanisms that do not directly involve signaling molecules. For example, receptor dimerization/oligomerization has been established as an important means to regulate the functional expression and/or differential signaling activities of certain GPCRs. ${ }^{[63,64]}$ It was shown that individual dopamine $D_{1}$ and $D_{2}$ receptors signal through $G_{\alpha_{s}}$ and $G_{\alpha i}$, respectively, but the $\mathrm{D}_{1} / \mathrm{D}_{2}$ heterodimer is instead activated through the $\mathrm{G}_{\alpha \mathrm{q}}$ pathway. ${ }^{[65]}$ Similarly, the $\mu-\delta$ opioid heterodimer was demonstrated to display a different pharmacologic profile from those of the $\mu$ - or $\delta$-homodimers. ${ }^{[66]}$ Functional complementation was observed when two mutant luteinizing hormone receptors (one can interact with ligand but cannot signal and the other is defective in ligand binding but able to signal) were co-expressed. ${ }^{[67]}$ Receptor oligomerization can also rescue and promote the surface expression of immature 
GPCRs to form a functional heterodimer. For example, when expressed alone, the metabotropic GABA $R_{B}$ isoform was retained in the endoplasmic reticulum (ER) as an immature receptor whereas the $\mathrm{GABA}_{B} \mathrm{R}_{2}$ isoform was expressed efficiently on the surface but could neither bind $\gamma$-Aminobutyric acid (GABA) nor induce signals. When the two isoforms were co-expressed, both receptors are delivered to the surface as a functional heterodimer capable of GABA binding and signaling. ${ }^{[68-71]}$ On the contrary, downregulation of functional GPCRs can be achieved when a dominant negative mutant GPCR is co-expressed and dimerized with the wild-type receptor, retaining the heterodimer in the ER ${ }^{[72,73]}$

Receptor oligomerization can also occur between GPCRs and non-GPCRs. During the search of a functional receptor for calcitonin-gene-related peptide (CGRP), it was found that the calcitonin-receptor-like receptor (CRLR), a secretin-class/class B GPCR, needs a co-receptor called receptor-activity-modifying protein 1 (RAMP1) to be efficiently expressed to form a functional CGRPR. ${ }^{[74]}$ Furthermore, when CRLR is dimerized with RAMP2/3, the heterodimers function as a receptor for adrenomedullin that is related to CGRP, but with a different pharmacological profile. ${ }^{[63,74]}$ More recently, many such RAMP-like nonclassical private GPCR chaperone/escort proteins were identified to interact and facilitate the intracellular trafficking and cell-surface expression of specific GPCRs. ${ }^{[23,28,63]}$ The realization that chaperone/escort proteins are needed for the functional expression of GPCRs has led to the development of small molecule pharmacological chaperones to rescue poorly expressed disease-causing mutant GPCRs.

In addition to the functional targeting to cell surface, GPCR expression and activity are also highly regulated by receptor internalization/endocytosis and post-endocytic trafficking. Thus, endocytic sorting can determine the cellular fates of GPCRs by targeting the receptors to lysosome for degradation or recycling to the cell surface. Again, many of these processes are regulated by GPCR-interacting proteins and represent potential targets for chemical intervention. ${ }^{[23,28]}$

\section{Conclusions}

GPCRs represent the largest group of cell membrane proteins in human proteome. By transmitting diverse ranges of extracellular signals, GPCRs are critical in cell growth, differentiation, migration, and death. In normal physiology, GPCRs are essential for numerous processes including embryonic development, immunological function, brain development, CNS function, and normal germ cell production. The expression and function of GPCRs are regulated at multiple points during the biosynthesis, intracellular trafficking, ligand binding, and the endocytosis pathway of receptors. GPCRs signal through diverse G-protein-dependent and G-protein-independent mechanisms that involve many intracellular messengers and adaptor proteins. Genetic mutations (deletion, insertion, splicing-defect, nonsense and missense mutations) that render GPCRs defective (totally or partially inactive, constitutively active, inefficient trafficking, etc.) have been increasingly linked to human diseases. Therefore, it is not surprising that GPCRs are the major targets of medicinal drugs currently in use or in development. With the critical findings of the two Nobel Laureates and many others, a much clearer picture is emerging as to how GPCRs work their molecular magic. It is expected that many more GPCRs will soon be deorphanized and structurally defined. As well, extensive GPCR-mediated signaling networks will be mapped in detail. Moreover, better and more specific drugs are being developed to modulate the functions of GPCRs and hopefully control/cure diseases. Therefore, it might not be unrealistic to expect another Nobel Prize in Physiology or Medicine for GPCR-related research in the future.

\section{Acknowledgments}

I thank Dr. Martin Stacey (University of Leeds, UK) and Dr. Gin-Wen Chang (Chang Gung University, Taiwan) for helpful discussion and critical reading of the manuscript. My research was supported by grants from National Science Council, Taiwan (NSC98-2320-B-182-028-MY3 and NSC101-2320-B-182-029-MY3), and Chang Gung Memorial Hospital (CMRPD1A0181). I apologize to the colleagues whose work could not be cited due to space limitations.

\section{REFERENCES}

1. Fredriksson R, Lagerstrom MC, Lundin LG, Schioth HB. The G-protein-coupled receptors in the human genome form five main families. Phylogenetic analysis, paralogon groups, and fingerprints. Mol Pharmacol 2003;63:1256-72.

2. Kroeze WK, Sheffler DJ, Roth BL. G-protein-coupled receptors at a glance. J Cell Sci 2003;116:4867-9.

3. Pierce KL, Premont RT, Lefkowitz RJ. Seven-transmembrane receptors. Nat Rev Mol Cell Biol 2002;3:639-50.

4. Lagerstrom MC, Schioth HB. Structural diversity of G protein-coupled receptors and significance for drug discovery. Nat Rev Drug Discov 2008;7:339-57.

5. Tyndall JD, Sandilya R. GPCR agonists and antagonists in the clinic. Med Chem 2005;1:405-21.

6. Hausch F, Holsboer F. The seven pillars of molecular pharmacology: GPCR research honored with Nobel Prize for chemistry. Angew Chem Int Ed Engl 2012;51:12172-5.

7. Baker EN, Dauter Z. Nobel Prize for Chemistry 2012: GPCRs seen through a crystal ball. Acta Crystallogr D Biol Crystallogr 2012;68:1439-40.

8. Buchen L. Cell signalling: It's all about the structure. Nature 2011;476:387-90.

9. Lefkowitz RJ. Historical review: A brief history and personal retrospective of seven-transmembrane receptors. Trends Pharmacol 
Sci 2004;25:413-22.

10. Lefkowitz RJ, Mukherjee C, Coverstone M, Caron MG. Stereospecific $(3 \mathrm{H})$ (minus)-alprenolol binding sites, beta-adrenergic receptors and adenylate cyclase. Biochem Biophys Res Commun 1974;60:703-9.

11. Lefkowitz RJ, Roth J, Pastan I. Radioreceptor assay of adrenocorticotropic hormone: New approach to assay of polypeptide hormones in plasma. Science 1970;170:633-5.

12. Lefkowitz RJ, Roth J, Pricer W, Pastan I. ACTH receptors in the adrenal: Specific binding of ACTH-125I and its relation to adenyl cyclase. Proc Natl Acad Sci U S A 1970;65:745-52.

13. De Lean A, Stadel JM, Lefkowitz RJ. A ternary complex model explains the agonist-specific binding properties of the adenylate cyclase-coupled beta-adrenergic receptor. J Biol Chem 1980;255:7108-17.

14. Caron MG, Lefkowitz RJ. Solubilization and characterization of the beta-adrenergic receptor binding sites of frog erythrocytes. J Biol Chem 1976;251:2374-84.

15. Caron MG, Srinivasan Y, Pitha J, Kociolek K, Lefkowitz RJ. Affinity chromatography of the beta-adrenergic receptor. J Biol Chem 1979;254:2923-7.

16. Cerione RA, Sibley DR, Codina J, Benovic JL, Winslow J, Neer EJ, et al. Reconstitution of a hormone-sensitive adenylate cyclase system. The pure beta-adrenergic receptor and guanine nucleotide regulatory protein confer hormone responsiveness on the resolved catalytic unit. J Biol Chem 1984;259:9979-82.

17. Cerione RA, Strulovici B, Benovic JL, Strader CD, Caron MG, Lefkowitz RJ. Reconstitution of beta-adrenergic receptors in lipid vesicles: Affinity chromatography-purified receptors confer catecholamine responsiveness on a heterologous adenylate cyclase system. Proc Natl Acad Sci USA 1983;80:4899-903.

18. Dixon RA, Kobilka BK, Strader DJ, Benovic JL, Dohlman HG, Frielle $\mathrm{T}$, et al. Cloning of the gene and cDNA for mammalian beta-adrenergic receptor and homology with rhodopsin. Nature 1986;321:75-9.

19. Kobilka BK, Frielle T, Dohlman HG, Bolanowski MA, Dixon RA, Keller P, et al. Delineation of the intronless nature of the genes for the human and hamster beta 2-adrenergic receptor and their putative promoter regions. J Biol Chem 1987;262:7321-7.

20. Lefkowitz RJ. Seven transmembrane receptors: A brief personal retrospective. Biochim Biophys Acta 2007;1768:748-55.

21. Nathans J, Hogness DS. Isolation, sequence analysis, and intron-exon arrangement of the gene encoding bovine rhodopsin. Cell 1983;34:807-14.

22. Stryer L. Cyclic GMP cascade of vision. Annu Rev Neurosci 1986;9:87-119.

23. Millar RP, Newton CL. The year in G protein-coupled receptor research. Mol Endocrinol 2010;24:261-74.

24. Kobilka BK, Kobilka TS, Daniel K, Regan JW, Caron MG, Lefkowitz RJ. Chimeric alpha 2-, beta 2 -adrenergic receptors: delineation of domains involved in effector coupling and ligand binding specificity. Science 1988;240:1310-6.

25. Cotecchia S, Ostrowski J, Kjelsberg MA, Caron MG, Lefkowitz RJ. Discrete amino acid sequences of the alpha 1-adrenergic receptor determine the selectivity of coupling to phosphatidylinositol hydrolysis. J Biol Chem 1992;267:1633-9.

26. Kjelsberg MA, Cotecchia S, Ostrowski J, Caron MG, Lefkowitz RJ.
Constitutive activation of the alpha 1B-adrenergic receptor by all amino acid substitutions at a single site. Evidence for a region which constrains receptor activation. J Biol Chem 1992;267:1430-3.

27. Rajagopal K, Lefkowitz RJ, Rockman HA. When 7 transmembrane receptors are not $\mathrm{G}$ protein-coupled receptors. J Clin Invest 2005;115:2971-4.

28. Ritter SL, Hall RA. Fine-tuning of GPCR activity by receptor-interacting proteins. Nat Rev Mol Cell Biol 2009;10:819-30.

29. Ostrowski J, Kjelsberg MA, Caron MG, Lefkowitz RJ. Mutagenesis of the beta 2-adrenergic receptor: How structure elucidates function. Annu Rev Pharmacol Toxicol 1992;32:167-83.

30. Strader CD, Fong TM, Tota MR, Underwood D, Dixon RA. Structure and function of $\mathrm{G}$ protein-coupled receptors. Annu Rev Biochem 1994;63:101-32.

31. Palczewski K, Kumasaka T, Hori T, Behnke CA, Motoshima H, Fox BA, et al. Crystal structure of rhodopsin: A G protein-coupled receptor. Science 2000;289:739-45.

32. Rasmussen SG, Choi HJ, Rosenbaum DM, Kobilka TS, Thian FS, Edwards PC, et al. Crystal structure of the human beta2 adrenergic G-protein-coupled receptor. Nature 2007;450:383-7.

33. Cherezov V, Rosenbaum DM, Hanson MA, Rasmussen SG, Thian FS, Kobilka TS, et al. High-resolution crystal structure of an engineered human beta2-adrenergic G protein-coupled receptor. Science 2007;318:1258-65.

34. Rosenbaum DM, Cherezov V, Hanson MA, Rasmussen SG, Thian FS, Kobilka TS, et al. GPCR engineering yields high-resolution structural insights into beta2-adrenergic receptor function. Science 2007;318:1266-73.

35. Rasmussen SG, Choi HJ, Fung JJ, Pardon E, Casarosa P, Chae PS, et al. Structure of a nanobody-stabilized active state of the beta (2) adrenoceptor. Nature 2011;469:175-80.

36. Jacoby E, Bouhelal R, Gerspacher M, Seuwen K. The 7 TM G-protein-coupled receptor target family. Chem Med Chem 2006;1:761-82.

37. Bockaert J, Pin JP. Molecular tinkering of G protein-coupled receptors: An evolutionary success. EMBO J 1999;18:1723-9.

38. Park JH, Scheerer P, Hofmann KP, Choe HW, Ernst OP. Crystal structure of the ligand-free G-protein-coupled receptor opsin. Nature 2008;454:183-7.

39. Scheerer P, Park JH, Hildebrand PW, Kim YJ, Krauss N, Choe HW, et al. Crystal structure of opsin in its G-protein-interacting conformation. Nature 2008;455:497-502.

40. Hanson MA, Stevens RC. Discovery of new GPCR biology: One receptor structure at a time. Structure 2009;17:8-14

41. Weis WI, Kobilka BK. Structural insights into G-protein-coupled receptor activation. Curr Opin Struct Biol 2008;18:734-40.

42. Coughlin SR. Thrombin signalling and protease-activated receptors. Nature 2000;407:258-64.

43. Macfarlane SR, Seatter MJ, Kanke T, Hunter GD, Plevin R. Proteinase-activated receptors. Pharmacol Rev 2001;53:245-82.

44. Lappano R, Maggiolini M. G protein-coupled receptors: Novel targets for drug discovery in cancer. Nat Rev Drug Discov 2011;10:47-60.

45. Congreve M, Marshall F. The impact of GPCR structures on pharmacology and structure-based drug design. Br J Pharmacol 2010;159:986-96. 
46. Kenakin T. Agonist-receptor efficacy. II. Agonist trafficking of receptor signals. Trends Pharmacol Sci 1995;16:232-8.

47. Millar RP, Pawson AJ. Outside-in and inside-out signaling: The new concept that selectivity of ligand binding at the gonadotropin-releasing hormone receptor is modulated by the intracellular environment. Endocrinology 2004;145:3590-3.

48. Millar RP, Pawson AJ, Morgan K, Rissman EF, Lu ZL. Diversity of actions of GnRHs mediated by ligand-induced selective signaling. Front Neuroendocrinol 2008;29:17-35.

49. Dorsam RT, Gutkind JS. G-protein-coupled receptors and cancer. Nat Rev Cancer 2007;7:79-94.

50. Goldsmith ZG, Dhanasekaran DN. G protein regulation of MAPK networks. Oncogene 2007;26:3122-42.

51. Caunt CJ, Finch AR, Sedgley KR, McArdle CA. Seven-transmembrane receptor signalling and ERK compartmentalization. Trends Endocrinol Metab 2006;17:276-83.

52. Wang K, Wong YH. G protein signaling controls the differentiation of multiple cell lineages. Biofactors 2009;35:232-8.

53. Belmonte SL, Blaxall BC. G protein coupled receptor kinases as therapeutic targets in cardiovascular disease. Circ Res 2011;109:309-19.

54. Gainetdinov RR, Premont RT, Bohn LM, Lefkowitz RJ, Caron MG. Desensitization of $\mathrm{G}$ protein-coupled receptors and neuronal functions. Annu Rev Neurosci 2004;27:107-44

55. Violin JD, Lefkowitz RJ. Beta-arrestin-biased ligands at seven-transmembrane receptors. Trends Pharmacol Sci 2007;28:416-22.

56. Hanyaloglu AC, von Zastrow M. Regulation of GPCRs by endocytic membrane trafficking and its potential implications. Annu Rev Pharmacol Toxicol 2008;48:537-68.

57. Bhola NE, Grandis JR. Crosstalk between G-protein-coupled receptors and epidermal growth factor receptor in cancer. Front Biosci 2008;13:1857-65.

58. Fischer OM, Hart S, Gschwind A, Ullrich A. EGFR signal transactivation in cancer cells. Biochem Soc Trans 2003;31:1203-8.

59. Blobel CP. ADAMs: key components in EGFR signalling and development. Nat Rev Mol Cell Biol 2005;6:32-43.

60. Short SM, Boyer JL, Juliano RL. Integrins regulate the linkage between upstream and downstream events in $G$ protein-coupled receptor signaling to mitogen-activated protein kinase. J Biol Chem 2000;275:12970-7.
61. Luo BH, Carman CV, Springer TA. Structural basis of integrin regulation and signaling. Annu Rev Immunol 2007;25:619-47.

62. Abram CL, Lowell CA. The ins and outs of leukocyte integrin signaling. Annu Rev Immunol 2009;27:339-62.

63. Bouvier M. Oligomerization of G-protein-coupled transmitter receptors. Nat Rev Neurosci 2001;2:274-86.

64. Ferre S, Baler R, Bouvier M, Caron MG, Devi LA, Durroux T, et al Building a new conceptual framework for receptor heteromers. Nat Chem Biol 2009;5:131-4.

65. Lee SP, So CH, Rashid AJ, Varghese G, Cheng R, Lanca AJ, et al. Dopamine D1 and D2 receptor Co-activation generates a novel phospholipase C-mediated calcium signal. J Biol Chem 2004;279:35671-8.

66. Jordan BA, Devi LA. G-protein-coupled receptor heterodimerization modulates receptor function. Nature 1999;399:697-700.

67. Lee C, Ji I, Ryu K, Song Y, Conn PM, Ji TH. Two defective heterozygous luteinizing hormone receptors can rescue hormone action. J Biol Chem 2002;277:15795-800.

68. Jones KA, Borowsky B, Tamm JA, Craig DA, Durkin MM, Dai $\mathrm{M}$, et al. GABA (B) receptors function as a heteromeric assembly of the subunits GABA (B) R1 and GABA (B) R2. Nature 1998;396:674-9.

69. Kaupmann K, Malitschek B, Schuler V, Heid J, Froestl W, Beck P, et al. GABA (B)-receptor subtypes assemble into functional heteromeric complexes. Nature 1998;396:683-7.

70. Kuner R, Kohr G, Grunewald S, Eisenhardt G, Bach A, Kornau HC Role of heteromer formation in GABAB receptor function. Science 1999;283:74-7.

71. White JH, Wise A, Main MJ, Green A, Fraser NJ, Disney GH, et al Heterodimerization is required for the formation of a functional GABA (B) receptor. Nature 1998;396:679-82.

72. Benkirane M, Jin DY, Chun RF, Koup RA, Jeang KT. Mechanism of transdominant inhibition of CCR 5-mediated HIV-1 infection by ccr5delta32. J Biol Chem 1997;272:30603-6.

73. Rodriguez-Frade JM, Vila-Coro AJ, de Ana AM, Albar JP, Martinez AC, Mellado M. The chemokine monocyte chemoattractant protein-1 induces functional responses through dimerization of its receptor CCR2. Proc Natl Acad Sci U S A 1999;96:3628-33.

74. McLatchie LM, Fraser NJ, Main MJ, Wise A, Brown J, Thompson N, et al. RAMPs regulate the transport and ligand specificity of the calcitonin-receptor-like receptor. Nature 1998;393:333-9. 